\title{
28 Research Square \\ Realization of Visible Light Integrated Circuits for All-Optical Haar Transform
}

\section{Ali Azimi Fashi}

Iran University of Science and Technology School of Electrical Engineering

Mohammad Hashem Vadjed Samiei ( $\sim$ mh_samiei@iust.ac.ir)

Iran University of Science and Technology School of Electrical Engineering https://orcid.org/00000001-9773-047X

\section{Antonio Teixeira}

University of Aveiro Department of Electronics Telecommunications and Informatics: Universidade de Aveiro Departamento de Electronica Telecomunicacoes e Informatica

\section{Research Article}

Keywords: Photonic integrated circuits, Optical Haar transform (HT), Visible spectrum, TriPleX technology, Multimode interference (MMI)

Posted Date: February 11th, 2021

DOl: https://doi.org/10.21203/rs.3.rs-219298/v1

License: (c) (i) This work is licensed under a Creative Commons Attribution 4.0 International License. Read Full License 


\section{Abstract}

Photonic integrated circuits have been designed, simulated and tested on TriPleXTM platform technology for implementing optical Haar Transform (HT) in the visible spectrum. Optical circuits contain the new building block (BB) designed using the multimode interference (MMI) structure performing optical $\mathrm{HT}$ on a pair of the optical signals. The Outputs of the BB demonstrates the sum and subtraction of the input signals according to the HT operation. 1st-order and 2nd-order optical HT achieved for the green light input signals. Simulation and experimental results have successfully validated designed photonic circuits capability in implementing optical HT.

\section{Full Text}

Due to technical limitations, full-text HTML conversion of this manuscript could not be completed. However, the manuscript can be downloaded and accessed as a PDF.

\section{Figures}

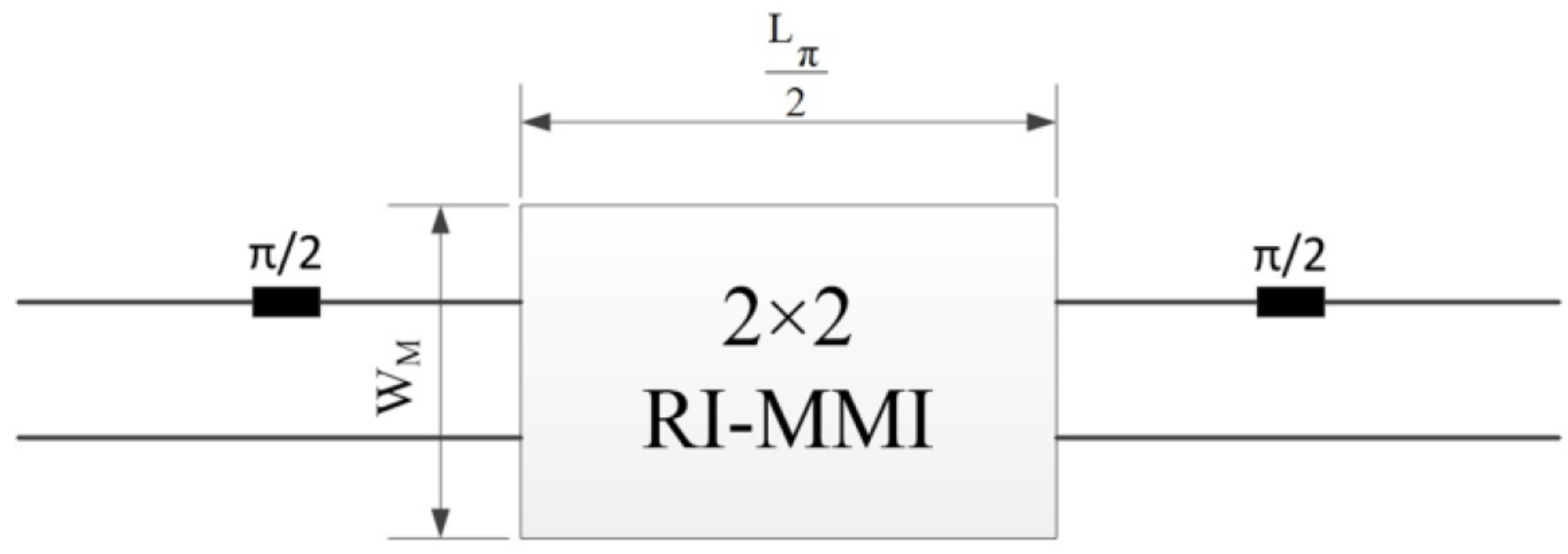

Figure 1

Diagram of the 2-point HT architecture (WM is width of the MMI), based in (Le 2010). 


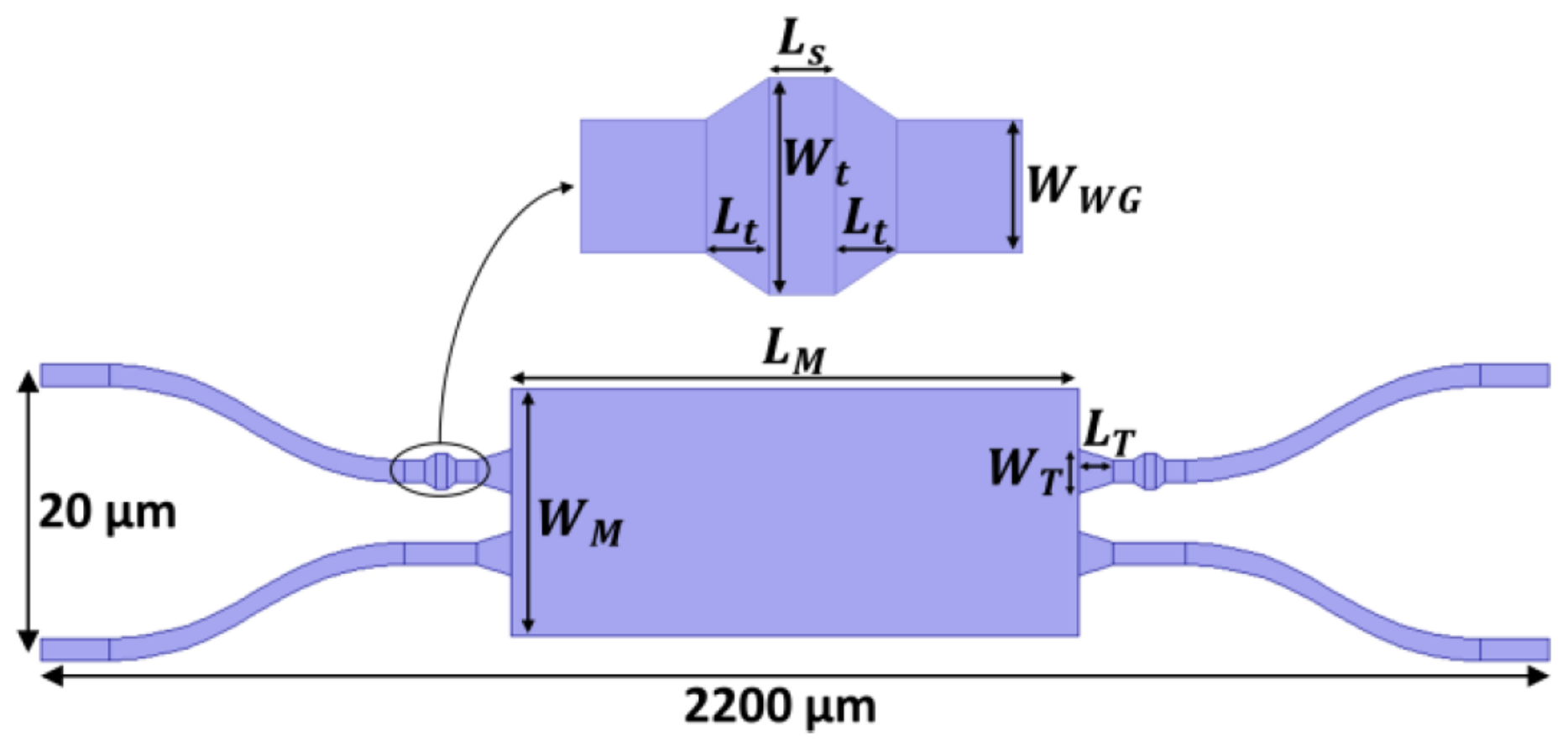

Figure 2

Layout of the designed optical HT BB.

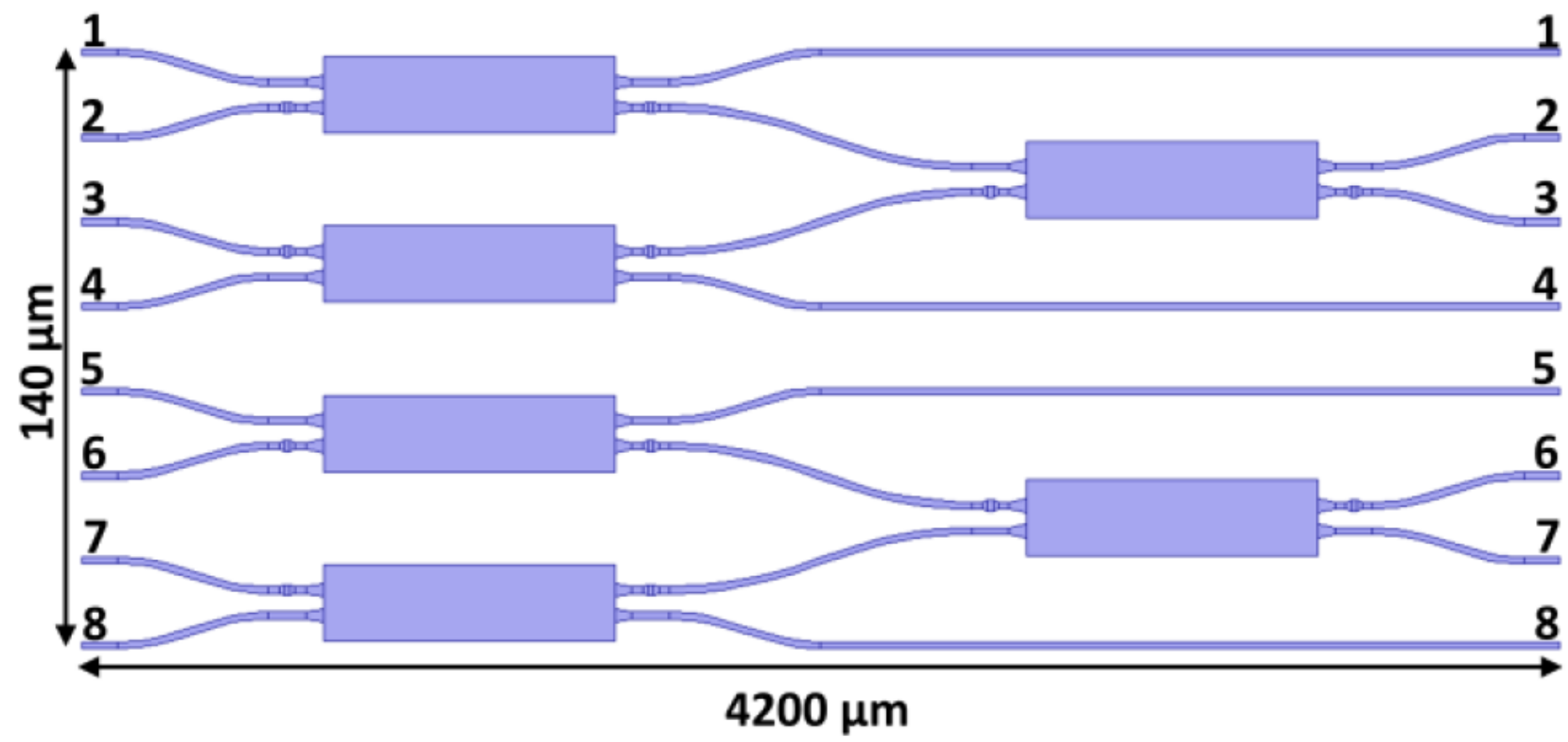

Figure 3

Layout of the 8-point HT photonic circuit. 


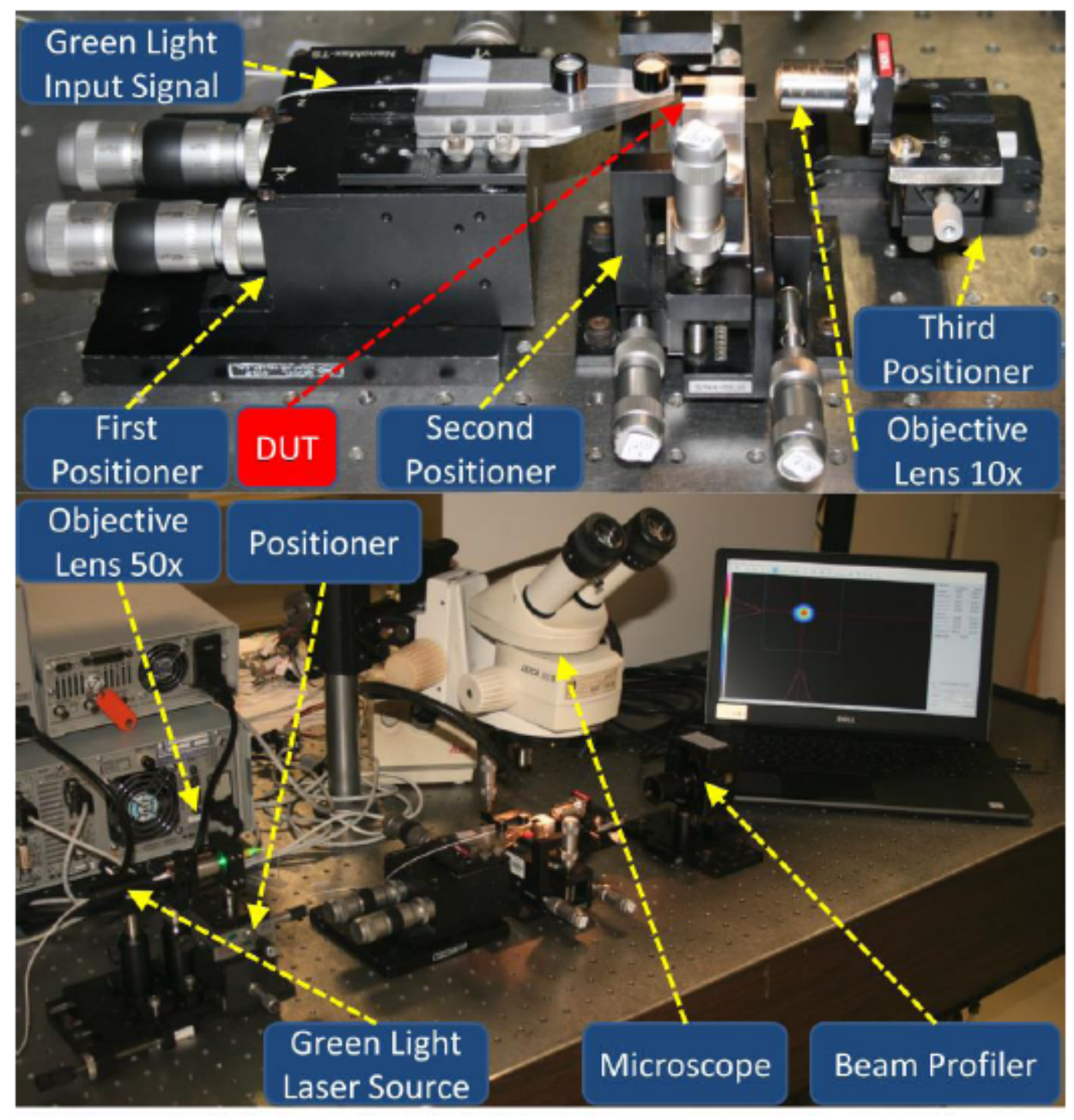

Figure 4

Setup for test and characterization of the fabricated photonic circuits. 


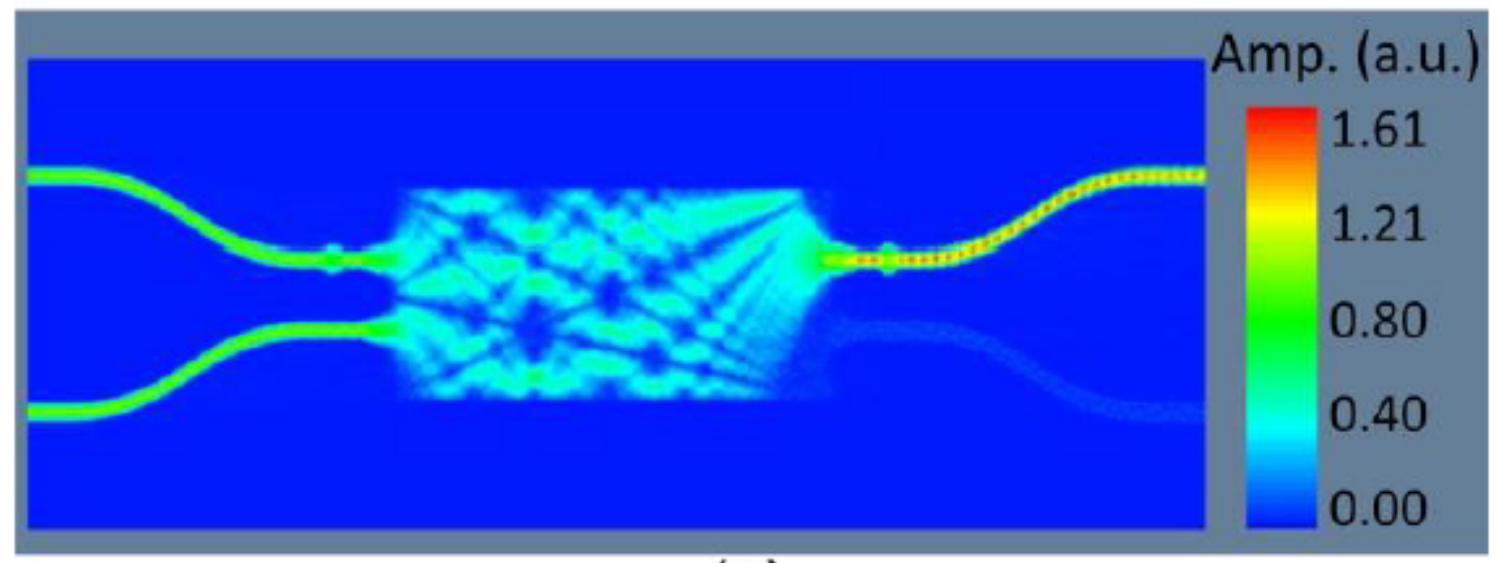

(a)

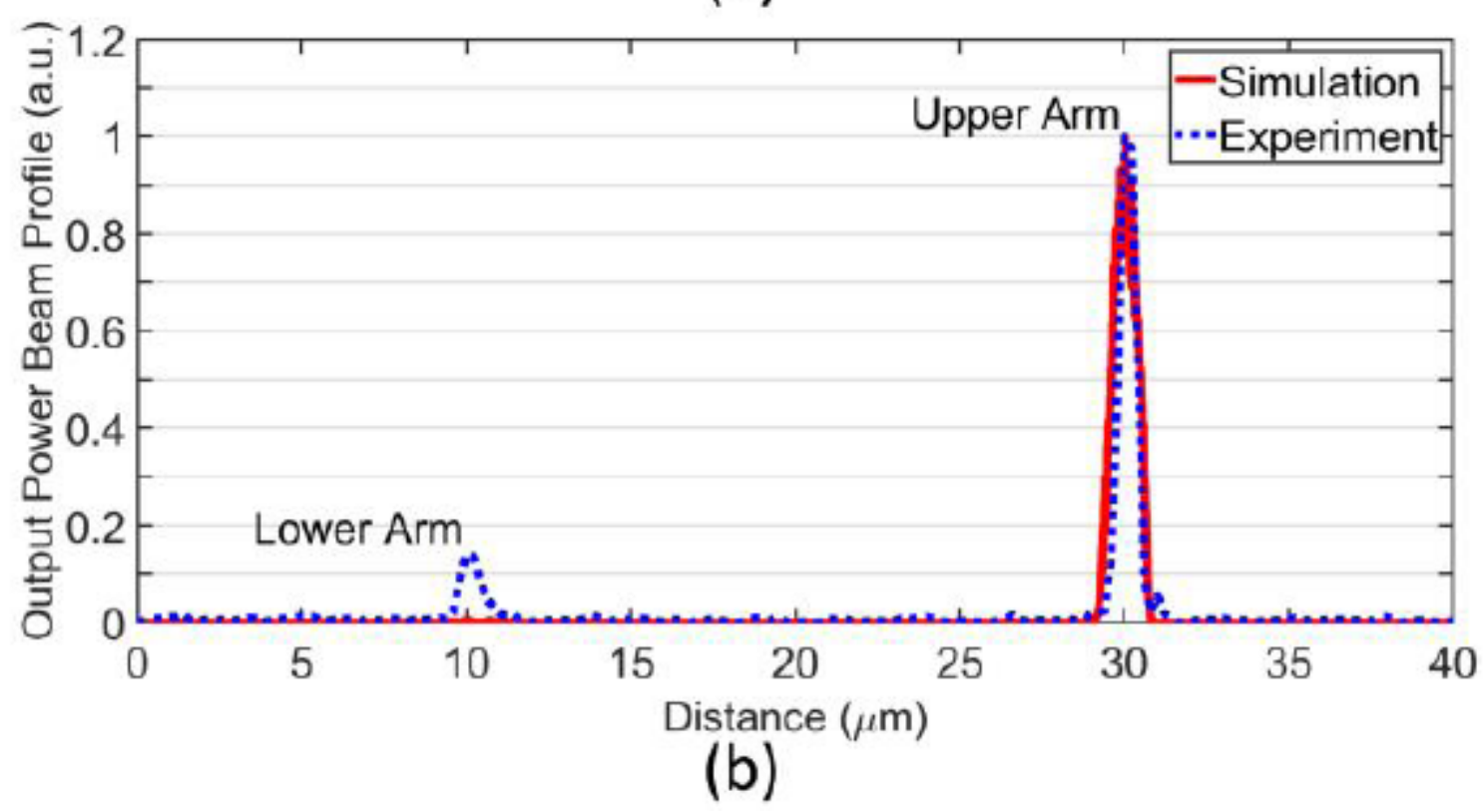

Figure 5

(a) Amplitude of the propagating optical field and (b) output power beam profiles of the 2-point optical BB. 


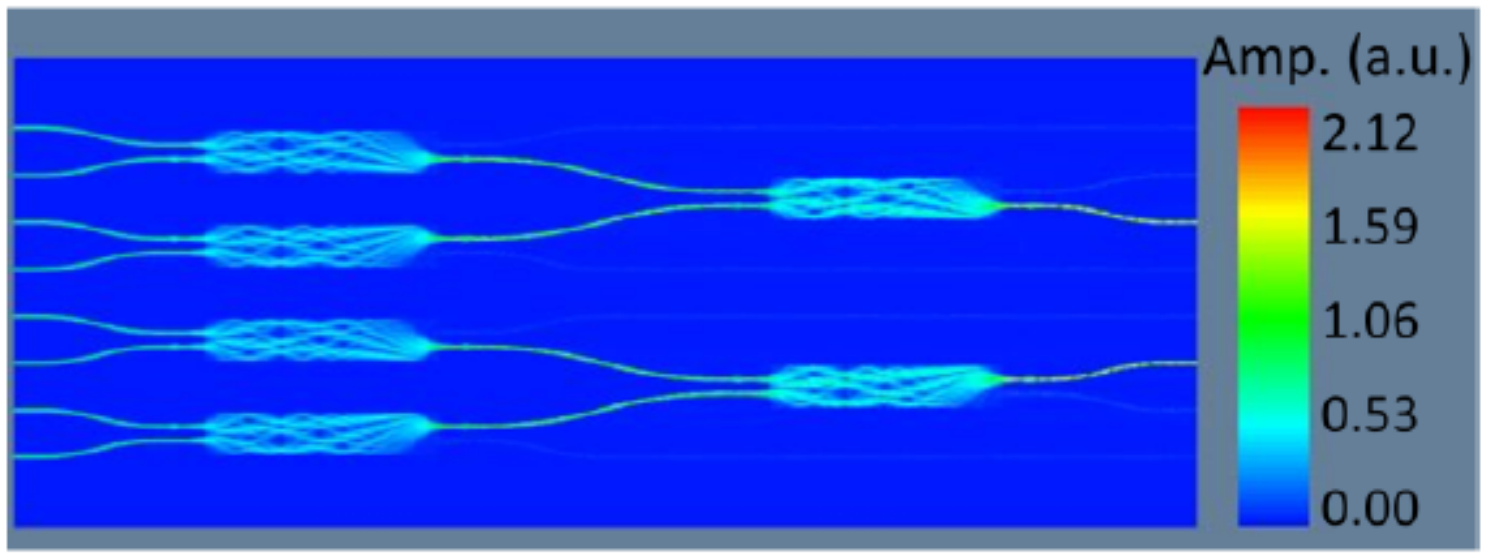

(a)

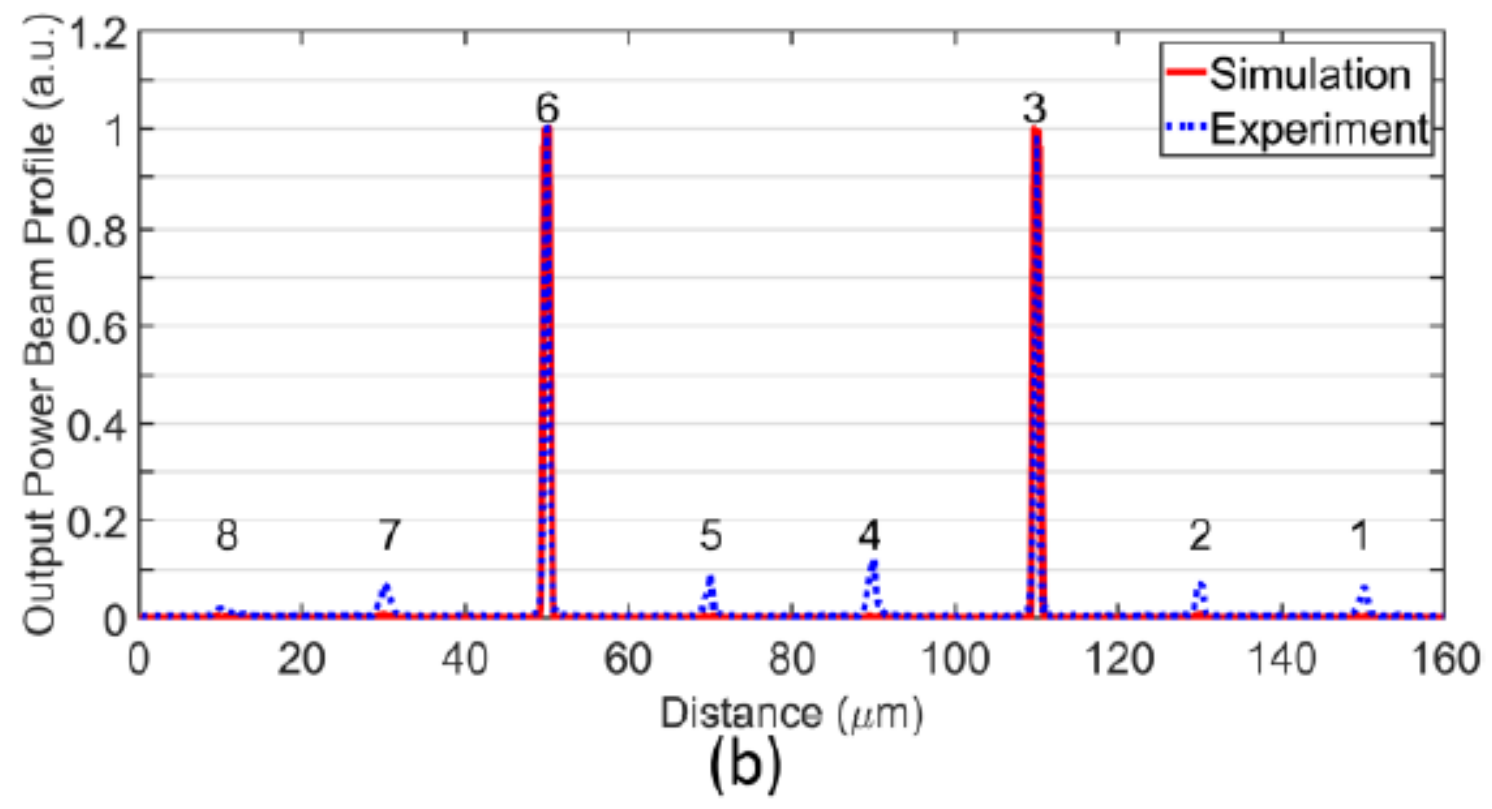

Figure 6

(a) Amplitude of the propagating optical field and (b) output power beam profiles of the 8-point HT circuit. 